\title{
El laberinto fúnebre de la frontera y la deshumanización del migrante en Las tierras arrasadas de Emiliano Monge*
}

\author{
The border death trap and the dehumanization of migrants in \\ Las tierras arrasadas by Emiliano Monge
}

Tatiana Calderón Le Joliff ${ }^{*}$, Julio Zárate ${ }^{* * *}$

\section{RESUMEN}

En este trabajo, buscamos analizar la poética de la muerte en los procesos migratorios contemporáneos representados por el ciclo infernal de los migrantes que cruzan la frontera en Las tierras Arrasadas (2015) del escritor mexicano Emiliano Monge. La lengua de la novela está compuesta por voces fragmentarias, testimoniales, murmullos de los vivos y de los muertos, cuyas historias son interrumpidas, devastadas. El valor testimonial cruza el límite de la ficción y da una dimensión distinta al relato al evitar la banalización de la violencia. Los cuerpos de los migrantes, residuales y despojados de sentido, están a la merced de seres abyectos. En el presente artículo, estudiaremos cómo el espacio trágico de la frontera recrea, en un relato frenético que se caracteriza por el delirio, la violencia y la pérdida de la esperanza, lo que el autor presenta como el "último holocausto de la especie" (341).
Palabras clave: frontera, migrante, cuerpo, testimonio, muerte

Este trabajo se enmarca en dos proyectos de investigación: Fondecyt Regular $\mathrm{n}^{\circ}$ 1151147 "Historia y memoria en la literatura de fronteras..., ejecutado por Tatiana Calderón Le Joliff en la Universidad Adolfo Ibáñez; y el proyecto sobre la representación de la migración centroamericana en la literatura mexicana contemporánea del coautor Julio Zárate, autorizado por el laboratorio LLSETI de la Universidad Savoie Mont-Blanc. ** Franco-chilena. Doctora en Literatura Comparada por la Universidad Paris 13Nord y la Pontificia Universidad Católica de Chile. Académica de la Universidad Adolfo Ibáñez, Santiago, Chile, tatiana.calderon@uai.cl.

*** Mexicano. Doctor en Literatura Hispanoamericana Contemporánea por la Universidad Paul Valéry Montpellier III. Académico de la Universidad Savoie Mont-Blanc, Chambéry, Francia, julio.zarate@univ-smb.fr. 


\begin{abstract}
In this work, we seek to analyze the poetics of death in the contemporary migratory processes represented by the infernal cycle of migrants crossing the border in las tierras arrasadas (2015) by Mexican writer Emiliano Monge. The language of the novel is composed of fragmentary voices, testimonials, murmurs of the living and the dead, whose stories are interrupted and devastated. The testimonial value crosses the limit of fiction and gives a different dimension to the story by avoiding the trivialization of violence. The bodies of migrants, residual and devoid of meaning, are at the mercy of abject beings. In the present article, we will study how, in a frenetic tale characterized by delirium, violence and the loss of hope, the tragic space of the border recreates what the author presents as our "species last holocaust" (341).
\end{abstract} Keywords: border, migrant, body, testimony, death 


\section{Introducción}

Las tierras arrasadas (2015), del escritor mexicano Emiliano Monge, explora la representación del mal y la poética de la muerte a través del recorrido migratorio contemporáneo. En este trabajo analizaremos la representación del calvario del sujeto migrante en el espacio laberíntico y deshumanizado de la frontera. Estela y Epitafio, personajes principales de la novela, son dos amantes sanguinarios, cuya infancia se desarrolló en el trauma de la violencia fronteriza. "Atraídos por el vacío deslucido e interminable" (Monge 138), se dedican a secuestrar y desplazar migrantes a través de un espacio que sugiere el límite entre Guatemala y México. La novela se estructura en tres libros que aluden a la Biblia: el libro de Epitafio, el libro de Estela y el libro de los Chicos de la Selva. Dos intermedios intercalados entre los libros ofrecen al relato una dimensión teatral. Las líneas principales de la novela confunden sus límites, haciendo de ellas un mismo relato frenético que se caracteriza por el delirio, la violencia y la pérdida de la esperanza.

El recorrido de los personajes de esta novela se realiza a través de una tierra de nadie donde reina la violencia. Monge plantea el cruce como una transgresión que conlleva al aniquilamiento, ya que atravesar la frontera geográfica implica, a la vez, el paso simbólico de la vida a la muerte. El relato se desarrolla alrededor de la frontera sur de México, pero la omnipresencia de la selva y del desierto hace posible la omisión del espacio referencial. Esto permite al autor construir una estructura dantesca en la que el espacio ficcional es descrito como un infierno o un laberinto fúnebre de tránsito sin salida, que sirve de sepultura para los migrantes. La idea del laberinto es reforzada por la presencia simbólica del Minotauro a través de Minos, nombre del vehículo en el que los migrantes son encerrados y devorados metafóricamente durante su recorrido a través de este espacio de barbarie.

Además del espacio físico, el autor desvela el infierno psicológico de los personajes, quienes buscan refugio en la memoria o en la promesa de un futuro lejos del engranaje criminal desplegado a lo largo del recorrido migratorio. No obstante, parece imposible escapar de la espiral de violencia en la que se sumergen los personajes de Las tierras arrasadas, donde los nombres de los secuestradores, así como los espacios por los que transitan componen un campo semántico de lo funerario: Estela, Epitafio, Cementeria, Mausoleo, Osaria. El lenguaje 
del relato se compone de una serie de voces fragmentarias, murmullos de los vivos y de los muertos, cuyas historias son interrumpidas, devastadas. Las lenguas de los perpetradores se enredan y participan de la cacofonía fronteriza que sumerge al sujeto en el miedo. Se aprecia de igual modo la presencia, en la ficción, de testimonios reales de migrantes, que se entrecruzan con los intertextos y alteran el ritmo del relato. Dichos testimonios reproducen la voz de las violadas, los mutilados, los muertos. Al cruzar el límite de la ficción, el testimonio da una dimensión distinta a la palabra, al prescindir de la banalización de la excesiva violencia y evitar que las voces de las víctimas se pierdan en el anonimato. Monge conjuga así el destino de los sinnombre con el de los migrantes centroamericanos.

La presencia de una serie de intertextos tomados del "Infierno" de la Comedia de Dante reafirma la noción del sufrimiento de los personajes que se extravían en la historia (170) y se encomiendan a un Dios ausente. Al cruzar la frontera, los migrantes inician un proceso de deshumanización que conlleva la pérdida de su identidad y la muerte. Los migrantes son definidos por sus carencias: sinvoz, sinnombre, sincuerpo; el cruce sella su destino al hacer de ellos "los hombres y mujeres que cruzaron las fronteras" (14). Monge habla de cuerpos cuyo andar es el rumor de quienes, sin saberlo, dirigen sus pasos al infierno. Los cuerpos de los migrantes, residuales y despojados de sentido, quedan a merced de seres abyectos que experimentan la metonimización de sus cuerpos, exponiendo la pérdida de sus capacidades cognitivas y habilidades racionales.

\section{Cruces geográficos: el laberinto fúnebre de la frontera}

Pese a la ausencia de referentes espaciales, el íncipit de Las tierras arrasadas sitúa a los personajes en un claro en medio de la selva, en algún punto de la frontera sur de México. Es ahí donde los esperan sus captores y da inicio su martirio. Estela, quien dirigirá uno de los convoyes de migrantes secuestrados, contempla las montañas, que aparecen "como muros que encierran la gran tierra lacrimante en que se encuentra" (22). La segunda parte de esta cita, en cursivas en el texto, proviene de la Comedia, a la cual Monge reenvía de forma sistemática para insistir en el carácter dantesco del recorrido migratorio. 
En su ensayo referente al imaginario del desierto, Rachel Bouvet destaca la dimensión física y espacial de la frontera, que describe como una zona de inestabilidad, un espacio de choque y de intercambio entre el yo y una alteridad que puede ser hostil. Dicha alteridad se manifiesta en un espacio sin contornos definidos. Bouvet evoca el vacío del desierto como un espacio "qui déclenche à la fois la perte des repères, la mise en échec des signes, autrement dit un processus de désémiotisation, de même qu'un questionnement existentiel faisant affleurer des interrogations sur le néant, le caractère insaisissable de l'être, l'altérité, la mort"1 (Bouvet 15-16).

Es posible encontrar un paralelo a esta idea en el extremo opuesto del desierto. En la novela la frontera se pierde en la selva, cuya exuberancia parece atrapar a los migrantes y devorarlos; nadie es testigo de los crímenes que suceden ahí, las huellas de los migrantes se pierden en la espesura, haciendo de este recorrido un laberinto. El crítico literario Jacques Poirier considera el laberinto como un espacio ambiguo, ni sellado ni abierto, un espacio horizontal donde "toute transcendance, invite à des parcours incertains, sans commencement ni fin" ${ }^{2}$ (Poirier, "Perdre le fil: Labyrinthes de..." 222). Esta ambivalencia, similar a la de la frontera, lo convierte en un paradigma de la exploración del significado del mundo y en la representación metafórica de las preocupaciones recurrentes de la modernidad, cuya racionalidad constitutiva aloja, a la vez, la confusión en su centro.

En Las tierras arrasadas prima lo irracional, la alteridad encuentra en la novela su expresión más radical en la violencia que busca la aniquilación del otro. La novela retrata un infierno circular cuya estructura es desvelada por el recorrido de los migrantes. El relato inicia con un secuestro en medio de la selva: "También sucede por el día, pero esta vez es por la noche" (13), y termina con un asesinato en masa, en el mismo espacio: “[...] les encajan los hocicos aún humeantes de sus fierros: también sucede por la noche, pero esta vez es por

\footnotetext{
"que desencadena a la vez la pérdida de referentes, el fracaso de los signos, dicho de otra manera, un proceso de desemiotización, al igual que un cuestionamiento existencial que hace surgir interrogantes sobre la nada, el carácter inasible del ser, la alteridad, la muerte" (nuestra traducción).

2 "toda trascendencia, invita a trayectorias inciertas, sin comienzo ni fin" (nuestra traducción).
} 
el día" (341). Esta suerte de quiasmo revela una alteración del orden que hace de la selva una entropía infernal. El lugar del secuestro, llamado "Ojo de Hierba" (13), también es conocido como "El Tiradero" (29), pues ahí los migrantes son despojados de sus pertenencias. Los dos chicos que hacen de "guías" de los migrantes recogerán los despojos, que venderán de nueva cuenta a sus futuras víctimas, aquellos que se preparan para adentrarse en la selva después de haber cruzado la frontera sur de México.

Desde el primer momento del secuestro en Ojo de Hierba, Epitafio, el jefe de los secuestradores, adopta una actitud despiadada: “ $\mathrm{Y} Y$ soy la patria! [...] - ¿Y qué quiere la patria? - La patria quiere que se hinquen" (26). Al presentarse como una personificación de la patria, Epitafio hace del país el verdugo de los migrantes. Esto reafirma la postura de autores como Alejandro Hernández, en Amarás a Dios sobre todas las cosas (2013) o Antonio Ortuño, en La fila india (2013) quienes también abordan en su obra el recorrido centroamericano y postulan que entrar en México es entrar en el infierno ${ }^{3}$. Los ecos de la novela de Monge al "Infierno" de Dante, considerado como un laberinto cuyos círculos concéntricos desvelan el eterno suplicio de los pecadores, subrayan el paralelismo con el recorrido migratorio y el sufrimiento de los migrantes.

Si bien la topografía es detallada, en Las tierras arrasadas la omisión deliberada del espacio referencial permite desplegar una geografía en la que cada espacio define la suerte de los migrantes: "la gente de la selva lo llama El Purgatorio" ${ }^{4 "}$ (300), el sitio en el cual los personajes se detienen a descansar antes de llegar al claro Ojo de Hierba. Los dos chicos que guían a quienes acaban de cruzar la frontera amenazan con abandonarlos si alguno se retrasa: "no saldrá nunca de aquí el que aquí se quede" (259), sentencia el menor de ellos. No son Virgilios, sino demonios que conducen al martirio. Del mismo modo, dentro de este espacio hay un "infierno". Así se le conoce al taller de carretera Tres

\footnotetext{
3 Cabe señalar también los puntos en común que presenta el relato del secuestro en la selva de Monge con el secuestro masivo de migrantes descrito en Amarás a Dios sobre todas las cosas (2013), en Alejandro Hernández. El líder de los secuestradores en Hernández exclama al ver llegar a los migrantes: "Bienvenidos al infierno" (233).

$4 \quad$ Monge hace referencia a dicho espacio al final de la novela para insistir en el ciclo infernal del recorrido migratorio que se repite sin cesar y que inicia con la llegada al claro Ojo de Hierba.
} 
Hermanos, "que devino gran deshuesadero" (176), un lugar donde además de desmontar autos los trillizos que, como Cerbero, cuidan del lugar, desmiembran los cuerpos que les llevan policías y delincuentes para luego quemarlos.

El secuestro en el claro Ojo de Hierba cambia la dinámica del desplazamiento, ya que los migrantes dejan de avanzar por la selva y son confinados en un tráiler y en un par de camionetas de carga para animales, para iniciar un recorrido plagado de tormentos, cuyo primer destino es El Teronaque, un antiguo matadero en medio de un bosque. Asimismo, el secuestro da inicio a un proceso de transformación que implica la pérdida de individualidad de los migrantes y una deshumanización que subraya su condición de víctimas. Cuando están en la selva los migrantes, denominados como "los hombres y mujeres que escaparon de sus tierras, unas tierras que hace tiempo fueron arrasadas" (26), conservan todavía un resto de humanidad: Quienaúnpresumedealma, Elquetieneaúnunnombre, LaquecuentaaúnconDios (339). No obstante, al ser secuestrados empiezan a desaparecer hasta convertirse en sinalma, sinvoz, sindios...

La sensación del encierro y el desconocimiento del espacio por el que transitan, aumentan la angustia y el miedo de los migrantes ante la crueldad de los verdugos. Tanto Epitafio como Estela se lanzan en un recorrido frenético cuya dimensión infernal se extiende por todo el territorio que controla la patria. El recorrido del tráiler que conduce Epitafio mientras vende a los migrantes desvela "las vastas tierras que separan El Infierno del lugar donde hace años alzó Estela la Carpa [...] ese lugar donde trabajan, como esclavos, varios cientos de migrantes" (279). A ese sitio se dirigen El Tampón y El Topo, dos policías contratados para asesinar a Estela; su muerte les permite controlar dicho lugar. El asesinato descubre la delgada línea que existe entre la ley y el crimen, pues policías y soldados están al servicio de la patria.

Aunado al espacio, Monge revela el infierno psicológico en el que se sumergen los personajes. La transformación evocada antes también afecta a los victimarios. El lugar que aparece como origen del crimen es El Paraíso, nombre del hospicio dirigido por el Padre Nicho. Estela va a este sitio para dejarle algunos de los niños secuestrados. Explotados y marcados por el punzón del padre, esos niños "su- 
surran y murmuran maldiciendo su existencia" (89). Epitafio y Estela también llevan las marcas "que acusan, ante el mundo y su memoria" (38), que también crecieron en El Paraíso. Los que pasan por este lugar, que aparece como otro laberinto, son marcados por el rencor, la venganza, el odio y la cólera. Ambos aceptan los designios del Padre Nicho, renunciando incluso a estar juntos, pues Epitafio se casa con una mujer que espera un hijo del cura. La imagen idílica del paraíso se invierte al revelarse como el eje del rencor y la pérdida de la esperanza. Desde el hospicio, el Padre Nicho controla la patria, ejerce el poder y el tráfico de personas con impunidad, haciendo de este sitio el paraíso del crimen, un lugar donde se corrompen las almas de los inocentes. Tanto Epitafio como Estela tratan de huir del pasado que los ata a este lugar y que vuelve, insistente, para atormentarlos: "El pasado está más cerca en la memoria que en el tiempo" (91). El laberinto plantea una dimensión espacio-temporal que hace imposible el escape.

En "La metamorfosis y el laberinto", Michel Foucault contrapone dos espacios míticos (Foucault 95): el espacio ordenado del laberinto de Dédalo y el espacio dúctil que propicia la metamorfosis del Minotauro. La figura del Minotauro sugiere la transformación del sujeto migrante durante el proceso de cruce fronterizo, que implica una potencial pérdida de identidad y, en el caso del secuestro en el relato, de su condición de individuo. Para Foucault, el Minotauro constituye un espejo de la muerte y del nacimiento; no obstante, en la novela, los migrantes están condenados y nada pueden esperar. Cabe mencionar el juego lingüístico que plantea el nombre del tráiler que conduce Epitafio. Las letras borradas dejan ver "el orador de minos", en lugar de "el devorador de caminos"; Minos, juez de los infiernos, también está presente en el infierno de Dante. Dentro de la máquina viajan los migrantes secuestrados y también aquel a quien Epitafio nombra Mausoleo, un ejemplo de la violencia circular, desmedida y a veces sin sentido presente en la frontera. Mausoleo es forzado a asumir la monstruosidad y el caos representado por el Minotauro; debido a su fuerza y su tamaño, el migrante pasa de ser víctima a ser verdugo de sus similares, de ser vigilado a vigilar; su empoderamiento lo hace incluso reconocer la debilidad de Epitafio y la traición que contra este prepara Sepelio. 
Por su parte, Epitafio y Estela son incapaces de alcanzar la redención que tanto anhelan: renunciar al crimen y alejarse de ese espacio infernal. El laberinto fúnebre del relato adquiere una dimensión trágica, reforzada por la estructura de la novela - dividida en tres actos y dos intermedios- que presenta una historia de amor desalmada entre dos huérfanos destinados al sacrificio. El amor de Epitafio y Estela es su única debilidad, lo único que les impide estar atentos a las señales de la traición que se cierne sobre ellos. Obsesionados por comunicarse, ambos se desgarran emocionalmente. El secreto de Estela, el embarazo que no puede comunicar a Epitafio, hace evidente la imposibilidad del renacimiento, que se confirma mediante la traición de Sepelio y el Padre Nicho, quien decide aniquilarlos para mantener el control del tráfico de migrantes. Monge pone énfasis en lo que Dante considera como el peor pecado: la traición, que se castiga en el noveno y último círculo del infierno.

Al describir con detalle la selva, la sierra y el avance de las horas, acompañadas por los cambios en los ruidos propios de la naturaleza, Monge provoca en la novela lo que Daniel-Henri Pageaux llama "effet exotique" $^{\prime 5}$ (Pageaux 101), un distanciamiento característico de la expresión de la alteridad. El autor construye una atmósfera que acentúa la impresión de aislamiento solo interrumpido por los ruidos de los hombres (golpes, gritos, disparos), que de tanto en tanto recuerdan su presencia. El efecto exótico, dice Pageaux, provoca una doble huida hacia otro tiempo y otro espacio, producto de la ensoñación del espectador; frente a esta imagen idílica, Monge describe un laberinto cuya violencia exige esta doble huida - a través de la memoria o la locura-, con el objetivo de escapar de la maldad que irradia de El Paraíso. La violencia adquiere una dimensión cíclica, que se repite con la llegada de un nuevo grupo de migrantes al claro Ojo de Hierba, el lugar donde dio inicio el secuestro.

El norte ni siquiera se menciona en Las tierras arrasadas, pues los migrantes tratan de sobrevivir a la crueldad de la patria; la entrada en este laberinto fúnebre da inicio a un proceso de deshumanización, asociado a la desintegración del lenguaje y al carácter residual de sus cuerpos, cuya única salida es la muerte.

"efecto exótico" (nuestra traducción). 


\section{Lenguas de ultratumba: el valor testimonial de la ficción}

La novela constituye una obra polifónica compuesta por un cruce entre lenguas testimoniales y ficcionales que terminan enredándose. Este tejido intertextual que subraya el autor en la nota final de la novela se refiere a fragmentos tomados de la Comedia, y de una serie de "citas tomadas de diversos testimonios de migrantes centroamericanos, a su paso por México" (342). Cada testimonio se adecua al desarrollo del relato, estableciendo un paralelismo entre la ficción y la realidad del fenómeno migratorio, lo cual permite también leer entre líneas la memoria del sujeto migrante que no sobrevivió. La ficción reproduce este testimonio de la muerte a través de la lengua de ultratumba, la faz oscura, el silencio significante del testimonio ausente.

Las lenguas de ultratumba están constituidas mayormente por los murmullos de los pecadores migrantes y traficantes. Así, se puede apreciar en esta obra prismática tanto la perspectiva del victimario que a su vez es víctima-, como la de los sujetos migrantes. El rumor de los murmullos - que acrecienta y disminuye como el zumbido de los tábanos y de las langostas en el texto-, recuerda otra gran novela fronteriza, Pedro Páramo de Juan Rulfo, cuyos murmullos matan y a la vez evocan la memoria de los muertos en un espacio ya aniquilado y desolado. Estas lenguas fragmentarias se unen para escuchar la canción infantil interpretada por Sepelio, el traidor encargado de sepultar a los migrantes:

empieza a mascullar la canción que canta en todas las descargas: “De tin marín de do pingüé”... los que vienen de otras patrias pero no de otras lenguas reconocen la canción que están cantando encima suyo y es así como comprenden que habrán de abandonar toda esperanza. (60)

La canción infantil mexicana, jitanjáfora que promueve el método de selección aleatoria para elegir al responsable de un evento, se convierte en una canción de tumba que se enlaza con la frase escrita en la puerta de entrada al infierno para los viajeros Dante y Virgilio: lasciate ogni speranza. Desde un principio, los que cruzaron las fronteras no tienen ninguna posibilidad de salir vivos del infierno fronterizo. En una primera instancia, se podría considerar a los migrantes como a 
nuevos pecadores, por haberse desarraigado. Los otros pecadores, más manifiestos, son los que infligen y que no quedaron en el oximorónico El Paraíso, el hospicio dirigido por el Padre Nicho, otro infierno más en las tierras arrasadas.

A estos murmullos de ultratumba de los pecadores migrantes, responden las lenguas enredadas de los perpetradores que recuerdan al gigante Nemrod, castigado por haberse opuesto a Dios. Nemrod, asociado a la construcción de la torre de Babel en el Antiguo Testamento, usa un lenguaje discordante, innoble, duro, que solo él entiende. La confusión lingüística surge entre Estela y el soldado cuyas lenguas se van superponiendo en la camioneta después de un momento tenso de "mutismo erizado" (73):

¡No me puedo yo ausentaremos, comeremos y llamaré de allí a Epitade mi retén toda la tarde y además toda lo normiré luego yo allí aunque sea un ratno deben saber que me he marchremos cuando sea luego otra vez por la nochllos me descubren me podrían llevar a juiando ya no sea tan peligroso andar afuera! (73)

Aquí se nota la intensidad de la conversación, el miedo de ambos personajes, así como la imposibilidad para comunicarse. Se augura en cierta forma el quiebre entre Estela y su propia organización corrupta. Algo similar sucede al final, cuando Sepelio, el traidor, se enfurece con Epitafio:

¿Cómo que si tengo luego... de qué mierda stáse hadlabno... móco equ si getno olueg de otar?, pregunta Sepelio enfurecido pero su lengua, tras meterse él también un par de puntas, enreda las palabras como se enredan ahora los potentes halos blancos del gran Minos y como se enredan las manos de Epitafio en el volante. (270)

El enredo lingüístico brota cuando los personajes se desenfrenan, se tensionan y muestran su fragilidad, tan inconmensurable como su crueldad. También indica la violencia de la acción de los perpetradores y la deslealtad y corrupción que subyacen en su actuar. Esta "pulsión de muerte" aparece también en la denominación de los personajes y espacios.

Monge establece un catálogo de nombres ligados a la empresa funeraria que emprendieron los huérfanos de El Paraíso. En un principio, parece carecer de un orden ostensible. Epitafio, Sepelio y Estela 
mueven a los migrantes como fardos de un lugar a otro sin que se entienda su andar, que hace recordar el camino laberíntico. Sin embargo, se vislumbra progresivamente un método que permite el desarrollo de la venta de estos migrantes por toda la región y especialmente en la Carpa, espacio de esclavitud.

Uno de los fenómenos más interesantes ligados al lenguaje en la obra es la puesta en escena de la metáfora gramatical. El narrador usa los sintagmas nominales o verbales y los convierte en una función denominativa, específicamente de nombre propio. Así tenemos a Oigosololoquequiero, Elsordodelamente, Laciegadeldesierto, Losqueaúntienenalma, LaqueadoraaEpitafio, etc. Este uso aumenta a medida que avanza el relato, provocando una extrañeza en la lectura y una aglutinación que se parece a la idea de masa indistinta en la que se van convirtiendo los cuerpos, que constituyen la moneda de cambio de los traficantes.

Más allá de las lenguas ficcionalizadas, dispuestas como cantinelas en la obra, la presencia del testimonio otorga una dimensión distinta al relato. Jean-Francois Chiantaretto entiende el testimonio como un “... récit à la première personne authentifié par la parole de celui qui raconte et qui garantit, par l'acte même le constituant comme témoin, l'existence de l'événement raconté" ${ }^{6}$ (Chiantaretto 11). Cada testimonio, añade, involucra al testigo, por lo que ha vivido y por lo que cuenta, pues el testimonio exige una responsabilidad con aquellos a quienes implica. En la novela, al igual que con los personajes, Monge no precisa el nombre ni la nacionalidad de quienes ofrecen el testimonio: solo aparece una serie de voces cuyas cursivas indican que el argumento no pertenece a la ficción. El autor insiste en el anonimato para subrayar la violencia que envuelve el recorrido.

Pese a tratarse de breves paréntesis que interrumpen la diégesis, su importancia reside en el cambio de percepción de la violencia, pues como Cathy Fourez señala, la barbarie no radica en el texto, sino en la vida misma. El texto, sin embargo, se vuelve fundamental para revelar una realidad silenciada: "Les corps sont faits aussi de mots qu'il faut

\footnotetext{
$6 \quad$ “... relato en primera persona autentificado por la palabra de quien cuenta y que garantiza, acto que lo constituye como testigo, la existencia del suceso contado" (nuestra traducción).
} 
creuser pour qu'ils puissent se libérer"7 (Fourez 102). Cada testimonio abre un paréntesis que es como una herida que reenvía a una realidad manifiesta en toda su crudeza. Baste citar uno de los testimonios que acompañan el relato de las violaciones:

Decían que si cooperábamos nos iba a ir mejor... eran mentiras... no paraban nunca... hasta que una ya no pudo... esta está más rica, dijeron [...] estaba en su mes y no les importó... todos la violaron... luego ella no volvió a pararse... está muerta ya esta puta, dijo uno y se marcharon.... (72)

Sobre la posibilidad de escribir la voz del otro, Chiantaretto señala: “Faire entendre la voix d'autrui, cela suppose de l'entendre dans sa propre voix, dans sa propre parole ; de même qu'à défaut de pouvoir s'entendre soi-même on peut se retrouver dans la voix des autres dans leur parole"8 (99). La ruptura ficcional desvela un mundo cuya brutalidad supera la ficción. Pese al silencio, la novela de Monge grita el dolor de las víctimas cuyas vidas son arrasadas.

La ausencia de voz es una de las características principales de su vulnerabilidad. En El Teronaque uno de los migrantes, paralizado por el miedo e incapaz de dar su nombre, es asesinado y "acepta ser ya solo el silencio de su paso por el mundo" (120). Frente a la imposición del silencio, cuando se encuentran solos, como durante el descanso en El Purgatorio, de inmediato se escucha "el nervioso despertarse de las lenguas de los hombres y mujeres que hace poco atravesaron el gran muro que divide en dos las tierras arrasadas" (303). Durante los breves periodos de calma, el recurso de la palabra refleja la imperiosa necesidad de existir: "soy de allá pero allá sí que no queda nada... por eso voy" (303). La justificación del viaje es una forma de aceptar el duro tributo que exige el recorrido: "Yo voy allá para olvidarme... [...] voy allá para ya no tener más miedo..." (303). A esta voz vulnerada, responde un cuerpo desechable, un fardo desplazado sin miramientos y más bien con crueldad, de un lugar a otro del laberinto fronterizo.

"Los cuerpos también están hechos de palabras que hay excavar para que puedan liberarse" (nuestra traducción).

$8 \quad$ "Hacer oír la voz de otro, esto supone escucharla en su propia voz, en la palabra propia; de igual forma, a defecto de poder escucharse a sí mismo, es posible encontrarse en la voz de otros, en su palabra" (nuestra traducción). 


\section{Cuerpos asolados: la deshumanización del migrante}

Los cuerpos de los sujetos migrantes resultan aniquilados en su tránsito por la frontera. La primera mención que se hace de "los que vienen de muy lejos" (13), subraya la extrañeza de quienes al internarse en la selva son guiados al infierno donde se pone fin a su libertad e inicia un proceso de deshumanización. Dicho proceso está ligado a la violencia infligida a sus cuerpos, que hace del cruce fronterizo el paso simbólico de la vida a la muerte. Con el secuestro comienza el "cantar de sus temores" (13). Al acercarse a ellos, Estela escucha "las más tímidas palabras, los alaridos sofocados, los acentos de temor, los suspiros y los ayes de los hombres y mujeres que escaparon de sus tierras" (24). La parte en cursivas de la cita proviene de la Comedia; los diferentes intertextos presentes en el relato hacen eco del concierto de lamentos que convierten el recorrido migratorio en una elegía colectiva.

El cuerpo, en la frontera, se puede leer desde el concepto de corpographèses que proponen Marie-Anne Paveau y Pierre Zoberman, "une véritable mise en forme langagière, textuelle et sémiotique des corps"9 (Paveau \& Zoberman 3). El cuerpo como contenedor y contenido, como metáfora, como espacio de modificación y de lenguajes diversos, donde el texto se puede literalmente proyectar, a través del tatuaje que se puede observar en la obra de Monge. En "Vidas residuales: el arte en tiempos de guerra. Las tierras arrasadas de Emiliano Monge”, Alina Peña Iguarán evoca una poética del residuo, referida al tratamiento de los cuerpos como excedentes incorporados y huellas remanentes de la violencia para instaurar la idea de desubjetivación (Giorgio Agamben) en la novela, sobre todo cuando el migrante es rebautizado desde la estética de la empresa funeraria.

En la novela los cuerpos reflejan los poderes del horror y el ejercicio de la abyección como lo plantea Julia Kristeva. Para la crítica, el cadáver es el colmo de la abyección porque representa la muerte infectando a la vida: "Étrangeté imaginaire et menace réelle, il nous appelle

\footnotetext{
9 “una presentación cabal lingüística, textual y semiótica de los cuerpos” (nuestra traducción).
} 
et finit par nous engloutir"10 (Kristeva 12). Los cadáveres rodean a los personajes de Las tierras arrasadas, tanto los victimarios como los migrantes, y provocan un miedo intenso ligado al poco valor que toma el cuerpo elegido para el trueque. Los dos personajes principales, Epitafio y Estela, pueden ser calificados como seres abyectos, arrojados fuera de un mundo al que no pertenecen y vagan constantemente:

Constructeur de territoires, de langues, d'oeuvres, le jeté n'arrête pas de délimiter son univers dont les confins fluides - parce que constitués par un non-objet, l'abject- remettent constamment en cause sa solidité et le poussent à recommencer. Bâtisseur infatigable, le jeté est en somme un égaré11 (16).

En el caso de los verdugos, sin embargo, sus construcciones son más bien destrucciones de territorios, lenguas y obras. Su único punto de arraigo es un amor intenso pero desestabilizador. Son seres abyectos tocados por lo sublime: "L'abject est bordé de sublime"12 (19), siempre al borde del abismo.

Dos tipos de cuerpos parecen emerger en la novela: los cuerpos bultos y los cuerpos órganos. Los cuerpos bultos desean ser un solo cuerpo (13), fundirse en una masa indistinta (16) para escapar de la muerte, la mutilación y la violación que aparece como castigo al igual que en el "Infierno" de Dante, cuando se fusionan dos cuerpos en uno. Los cuerpos bultos (36) son cuerpos asustados, enmudecidos, violentados, vaciados de su sentido: "toca acabar de enmudecerlos ... castigarles la cabeza ... volverlos ahora nadie" (81). Los cuerpos bultos, en cierta medida, ya están muertos. Emiten sonidos inconexos desde su prisión de lona, para luego ser silenciados: "El concierto de sonidos que sus cuerpos arrancaron al acero hace que adentro del conteiner, los que dejaron hace varios días sus tierras, lloren y hablen cada uno aisladamente: saben que eso que ahora escuchan es la simiente de otra

\footnotetext{
10 "Extrañeza imaginaria o amenaza real, nos convoca y termina por sumergirnos" (nuestra traducción).

11 "Constructor de territorio, de lenguas, de obras, el arrojado constantemente delimita su universo cuyos confines fluidos - porque constituidos por un no objeto, lo abyecto- cuestionan continuamente su solidez y lo empujan a empezar de nuevo. Arquitecto incansable, el arrojado es finalmente un extraviado" (nuestra traducción).

12 "lo abyecto está bordeado por lo sublime" (nuestra traducción).
} 
infamia" (56). Ya nos les queda esperanza, son residuos de la empresa funeraria, des/habitantes en esta tierra ajena.

En el claro Ojo de Hierba, Epitafio constata que "no habían sido nunca tantos" (16). Cada nueva oleada de migrantes disminuye su valor y recrudece la violencia. Sobre la condición del migrante, Fourez señala que "Dans l'exil de la pauvreté, s'est instaurée une chasse aux sujets qui vont ailleurs et qui, au cours de leur périlleux cheminement, deviennent du gibier possible et facile, pour avoir atteint le point culminant de la vulnérabilité : sans papiers, sans toit, sans place" ${ }^{13}$ (206). En total, Estela cuenta 74 hombres, mujeres y niños, destinados a su venta y castigo. Al caer en manos de los secuestradores, el miedo hace de ellos un mismo cuerpo uniforme "se acercan más y más unos a otros, convirtiendo en uno solo sus temblores y en una sola sus voces huecas" (14). Monge insiste en la pérdida de individualidad ante la suerte compartida; todo rasgo personal se vuelve superfluo ante la violencia que los convierte en "masa" (26). Las mujeres llevan la peor parte, pues constituyen el botín de los secuestradores: "debe haber como cincuenta... menos esas que ya se hayan acabado mis muchachos" (72). Lo anterior lo explica Estela al Chorrito, el capitán de un retén que también exige su pago. Las violaciones se repiten sin descanso y el autor recurre a la imagen del depredador y del carroñero en la selva para reforzar la condición de presa y víctima de las mujeres. El cuerpo, como señala Fourez, se vuelve el lugar privilegiado del verdugo, espacio del desahogo del crimen. Reiteradamente se exponen los testimonios de las violaciones de las mujeres (116), cuya mutilación no parece tener fin.

La pesadez de estos cuerpos (89) indica su condición pasiva, de carga muerta, de cadáver. Afirma Fourez, "Profaner le corps étranger jusqu'au sommet de la frénétique transgression, c'est nier l'individu"14 (264). Monge insiste en esta negación no solo a través de la excesiva violencia —en la novela apenas aparece el término "migrante"15_;

\footnotetext{
13 "En el exilio de la pobreza se ha instaurado una caza a los sujetos que van hacia otro lugar y que, en el transcurso de su peligroso desplazamiento, se vuelven presas posibles y fáciles, por haber alcanzado el punto álgido de la vulnerabilidad: sin documentos, sin techo, sin lugar" (nuestra traducción).

${ }_{14}$ "Profanar el cuerpo extranjero hasta el súmmum de la frenética transgresión, es negar al individuo" (nuestra traducción).

15 La palabra migrante figura en cuatro ocasiones: p. 142, 155, 205 y 279 de nuestra edición.
} 
en cambio, el autor recurre a una serie de eufemismos que lo definen por sus carencias y su distintivo principal: haber cruzado la frontera. Ningún nombre se menciona en el relato, ninguna historia personal es narrada. Los eufemismos dan cuenta de la degradación de su situación ante las vejaciones. Los migrantes se convierten en "sinnombre" (74), término presente también en la Comedia, "sinvoz" (119), "sincuerpo" (157), empleado principalmente para las mujeres, "sindios" (189), "sinalma" (196), que insiste en la pérdida de la fe y la esperanza.

Del grupo de migrantes, uno destaca por su gran tamaño. El único sobreviviente es el cuerpo desmesurado, el cuerpo del gigante, excampeón local de boxeo, quien luego de una catarsis de miedo, con lágrimas y vómito, abandona su humanidad empática y se metamorfosea en Mausoleo, el nuevo victimario, aparentándose a uno de los gigantes del octavo círculo del "Infierno" de Dante. Epitafio lo separa de las víctimas para convertirlo en el nuevo verdugo, lo llama Mausoleo y lo obliga a ver los castigos: “¿Qué van a hacer? —iDirás: qué vamos a hacerles! —corrige Epitafio [...]: toca acabar de enmudecerlos... castigarles la cabeza... volverlos ahora nadie" (81). Pese a sus dudas iniciales, Mausoleo se transforma en victimario y mata para sobrevivir, pues no quiere volver con los caídos. Más adelante será él quien vigile: "el que entre ciegos es ahora un nuevo ciego" (80). El primer asesinato de uno de sus pares termina la transformación "del que fue rebautizado, [...] Mausoleo $^{16}$, se repite las palabras que Epitafio le dijera: iquita esa cara y saca el pecho... te libero de seguir siendo como ellos!" (103). La impresión posterior de que es otro insiste sobre la distancia que lo separa de las víctimas y que se establece al aceptar el crimen.

La llegada a Ojo de Hierba es el punto de inflexión en el proceso de deshumanización. Cuando los chicos de la selva guían al nuevo grupo que acaba de cruzar la frontera hacia este punto, el autor los determina evocando aquello que poseen: "Elquetieneaúnunnombre" (258), "laquecuentaaúnconDios" (258), "Quienaúnpresumedealma" (258), "elquetienetodavíacuerpo" (258), "laquetieneaúnsusombra" (259). El uso del adverbio temporal en los nombres subraya la inmi-

${ }_{16}$ Él no es el único que tiene un nombre y una oportunidad de sobrevivir. El Merolico, un antiguo soldado que predice la buena fortuna, sobrevive al tiroteo (231) y es vendido a los trillizos, pero termina enloqueciendo al recordar su pasado como paramilitar (249252). 
nencia del cambio. Los verdugos que llevan la muerte en el nombre (Epitafio, Sepelio, Nicho, Estela...) son el límite, el fin del camino. Tras el descanso en el Purgatorio, la llegada a Ojo de Hierba destaca la inminencia de la pérdida: "Elqueusarayamuypocosulengua" (340) observa con horror unas fosas repletas de cadáveres y presiente el inicio de su desgracia.

Los cuerpos órganos corresponden a los perpetradores, designados por sus características corporales, sobre todo Estela. "LaqueadoraaEpitafio" es sorda y nombrada también como "Oigolosololoquequiero", alusión irónica a sus prótesis que le permiten oír o no al mundo que le rodea. Se volverá, al final de la novela, "Laciegadeldesierto", cuando se quite la vista al enterarse de la muerte de Epitafio, su amante. Es interesante observar que su calificación es anterior a su gesto. Es decir, en una especie de presagio, el nombre precede el acto de enceguecerse. Al hacerlo, queda totalmente amurallada en su propio cuerpo, sin vista, ni oído ya que ha perdido sus prótesis huyendo de los traidores.

Epitafio no tiene una invalidez orgánica, pero sí una mental. Se representa como "Elsordodelamente", haciendo un esfuerzo enorme para bloquear sus recuerdos que sin embargo lo vuelven loco. Su rostro consta de rasgos caricaturescos, desmedidos (15). Los dos protagonistas ostentan tatuajes (38) de su pasaje por el hospicio de El Paraíso. Niños abandonados y marcados, como en los campos de concentración, por el Padre Nicho, quien luego los usa como soldados de la frontera. Los tatuajes representan su memoria y al verlos recuerdan su pasado traumático. Estos cuerpos, también violentados y mutilados, sufren trastornos de sueño (49) y viven en la vigilia permanente (93). Personajes desbordados emocionalmente se convierten en animales, en una jauría enloquecida (125) que deambula, con afanes mortíferos, en el laberinto de la frontera. Peña Iguarán subraya los modos de hacer morir en contextos de colonialidad (Achille Mbembe) y que radican en una industria de los cuerpos y sus vidas que involucran las tecnologías de la necro-máquina. Esta narrativa escatológica se aparenta a una tragedia griega cuyo relato es desarticulado.

\section{Conclusión}

Una de las mayores dificultades que exige el tratamiento del tema migratorio es quizá la forma de representar la violencia, ya que como se- 
ñala Fourez, escribir la violencia cualquiera que sea su contexto, hace que lo banal linde con lo horrible. "Quelle écriture dans une société de violence?"17. Esta pregunta sirve de punto de partida a Marie-José Hanaï en un artículo inédito acerca de esta novela. La ficción, dice, da cuenta de la violencia "du terrifiant constat préalable à toute analyse littéraire d'une œuvre fictionnelle dont la base référentielle est ce phénomène $\mathrm{e}^{\prime 18}(3)$. Algunos autores que han escrito en torno al paso de los centroamericanos por México recurren de forma directa o indirecta al testimonio o a la investigación periodística con el objetivo, quizá, de fundamentar lo narrado. Establecer un vínculo con la realidad aparece como un recurso que evita caer en la banalidad.

En el caso de Ortuño y Monge los migrantes hablan poco, lo que pone de manifiesto la dificultad que existe en dar la voz a otro o en hablar en su lugar. El testigo, dice Chiantaretto, "raconte ce que nul autre ne peut raconter à sa place" ${ }^{19}$ (13). El relato de Monge no es, stricto sensu, sobre el viaje migratorio. El cruce fronterizo no lleva a los Estados Unidos, sino a la muerte en un espacio donde el crimen y la maldad no tienen límites. Los sinvoz que se adentran en el espacio mexicano se vuelven portavoces del drama migratorio. La oscuridad que envuelve al claro Ojo de Hierba una vez que el secuestro termina "sumerge al mundo en su ceguera" (29). Monge denuncia la ignominia del mundo que parece obstinarse en ignorar lo que sucede. Su escritura busca evitar que esos gritos se pierdan en la selva: contar su historia, dice el autor, es contar la historia "del último holocausto de la especie" (341).

Monge también expone en esta novela la aniquilación del lenguaje y del cuerpo. En el laberinto fúnebre de la frontera, la puesta en escena es trágica: tres actos y dos intermedios para relatar la historia de amor fracturada de dos huérfanos destinados a dar y recibir una muerte brutal. El autor privilegia la relación entre Epitafio y Estela y la traición que se cierne en torno a ellos, relegando el recorrido a un plano secundario. Los migrantes, que apenas son nombrados, forman parte del decoro; su aniquilamiento es el telón de fondo del infierno del traficante de

\footnotetext{
17 “¿Qué tipo de escritura para una sociedad de violencia?” (nuestra traducción).

18 "de la terrible constatación previa a cualquier análisis literario de una obra ficcional cuya base referencial sea este fenómeno" (nuestra traducción).

19 "cuenta lo que nadie más puede contar en su lugar" (nuestra traducción).
} 
personas, habitado por la violencia e incapaz de sentir compasión por quienes están condenados al anonimato y al silencio. La violencia circular, desmedida y a veces sin sentido presente en la frontera privilegia, sobre el orden del Laberinto, el caos representado por el Minotauro, una monstruosidad y una abyección sublime, proyección desatada de las convulsiones contemporáneas.

\section{Referencias bibliográficas}

Bouvet, Rachel. Pages du sable. Essai sur l'imaginaire du désert. Montréal, XYZ, 2006.

Chiantaretto, Jean François. Le témoin interne. Trouver en soi la force de résister. Mayenne, Flammarion, 2005.

Dante, Alighieri. Comedia. Prólogo, comentarios y traducción de José María Mico. Barcelona, Editorial Acantilado, 2018.

Foucault, Michel. “La metamorfosis y el laberinto". Trad. Patricio Canto. Raymond Roussel. Buenos Aires, Siglo XXI, 1976, pp. 90-113.

Fourez, Cathy. Scènes et corps de la cruelle démesure: récits de cet insoutenable Mexique. Paris, Mare \& Martin, 2012.

Hanaï, Marie-José. “Traverser l'enfer mexicain: les voix des migrants dans l'univers de la fiction (Las tierras arrasadas d'Emiliano Monge)". Revue Atlante, no. 11, 2019. En prensa.

Hernández, Alejandro. Amarás a Dios sobre todas las cosas. México D.F., Tusquets, 2013.

Kristeva, Julia. Pouvoirs de l'horreur: Essais sur l'abjection. Paris, Seuil, 1980.

Mbembe, Achille. Necropolítica. Sobre el gobierno privado indirecto. Buenos Aires, Melusina, 2011.

Monge, Emiliano. Las tierras arrasadas. México, D.F., Random House, 2015.

Ortuño, Antonio. La fila india. México, D.F., Conaculta-Océano, 2013.

Pageaux, Daniel-Henri. “Exotismes d'hier et d'aujourd'hui”. Françoise Aubès et Françoise Morcillo (Dirs.). Si loin si près: L'exotisme aujourd'hui. Clamecy, Klincksieck, 2011.

Paveau, Marie-Anne \& Zoberman, Pierre. "Corpographèses ou comment on/s'écrit le corps". Itinéraires, no. 1, 2009, pp. 7-19.

Peña Iguarán, Alina. "Residual lives: Art in times of war. Las tierras arrasadas (2015) by Emiliano Monge". Mitologías hoy: Revista 
de Pensamiento Crítico y Estudios Literarios Latinoamericanos, no. 17, 2018, pp. 135-149.

Poirier, Jacques. "Perdre le fil: Labyrinthes de la littérature française moderne". Amaltea Revista de Mitocrítica, no. 1, 2009, pp. 215-226.

Rulfo, Juan. Pedro Páramo. Edición de José Carlos González Boixo. Madrid, Cátedra, 2005. 